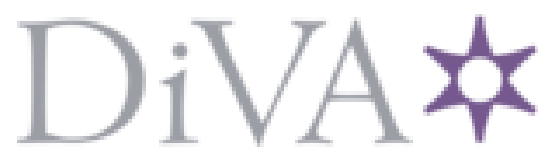

http://www.diva-portal.org

This is the published version of a paper published in International Journal of Martial Arts.

Citation for the original published paper (version of record):

Stenius, M., Dziwenka, R. (2015)

"Just be Natural With Your Body": An Autoethnography of Violence and Pain in Mixed Martial Arts.

International Journal of Martial Arts, 1: 1-24

Access to the published version may require subscription.

N.B. When citing this work, cite the original published paper.

Permanent link to this version:

http://urn.kb.se/resolve?urn=urn:nbn:se:umu:diva-107584 


\title{
"Just Be Natural with Your Body" An Autoethnography of Violence and Pain in Mixed Martial Arts
}

\author{
Authors: Magnus Stenius $1^{\text {st }}$, Umea University, magnus.stenius@umu.se \\ Ronald Dziwenka $2^{\text {nd }}$, New Mexico State University, dziwenka@nmsu.edu
}

Received: May 27, 2014 Accepted: August 10, 2015 Published online: August 27, 2015

\begin{abstract}
The aim of this article is to investigate bodily experiences through an autoethnographic fieldwork study in a mixed martial arts (MMA) club, and to analyze what experiences of pain can contribute to the understanding of the phenomenon of MMA in general and the violence associated with the sport in particular.

We argue that the experience of pain can give one the opportunity to sense the emotional and instrumental effects of MMA practice. We have crafted a definition of scripted violence in MMA, comprehended the body's development and evaluated the bodily accomplishments gained from the fighting process.

Informed by Julia Kristeva's notion on horror and Maurice Merleau-Pontys' phenomenology of the body, we discuss the concept of "stained-violence" by applying an inter-subjective approach to the notion of a body's inner abject.

The autoethnographical knowledge we acquired in this study allows us to assert that a researcher's own bodily reformation is an important asset to apply to examine the consequences of engaging in MMA training. We also apply a body-based method of performing autoethnographic research in order to examine the kinds of bodily improvements that can develop through MMA practice.
\end{abstract}

Keywords: abject, autoethnography, MMA, pain, stained-violence.

\section{Introduction}

With my heart pounding, I go down the stairs to the basement where the local MMA gym is located. I am nervous, and am wondering if they're going to be nice to me or beat me up? Then coach "Chris" welcomes me with a smile, "Hey man, nice to see you here. You can start by changing in the locker room to the left, then just jump in with us!"

(Field-notes, September 2010).

One of us (Magnus) was an ethnographer doing fieldwork "on the inside," in the sport of mixed martial arts (MMA) for twenty months. He had had this type of experience before, of experimenting with his body, as a young boy practicing karate and "going inside" the field with body and senses. He confronted his "gendered and constituted... [and] material embodied self" in the experience of disciplined "violence" in the gym (Woodward 2008, 543) by sharing "masculine space in the gym" with others.

By doing this study with Magnus as a participant-observer (sometimes in the text also referred to as "the ethnographer" or "the researcher"), we argue in our joint analysis for the potential of personal autoethnographic performance as a method of inquiry. We define ethnographic performance as the convergence of the "autobiographic impulse" and the "ethnographic moment in doing-fighting-yourself", epitomized through movement and critical self-reflexive discourse in performance (Muncey 2010, 10-11). 


\section{Inter-Somatic Play}

While collecting field data, Magnus' body was a working instrument through which the somatic responses unfolded. Accordingly, by being a part of the participants' bodily responses, he could begin to understand how we two together could analyze and resolve violence, how abjection and pain would unfold, and how we would understand stained-violence.

These concerns guided Magnus' coding of field notes and interview transcripts, and eventually led to the creation of a set of typologies for what the participants experienced. The inner participant observation methodology facilitated diachronic understanding, and this allowed him to observe, and participate in, the ways in which fighters learn bodily understanding and transform themselves into bodies capable of experiencing pain from "inside" violent forces. Later we came to understand that fighters withstand the abjections of the rigorous sport by gaining possession of the brutal and violent framework (Buse 2006).

As a participant researcher, Magnus explored the settings in which the data were collected and contested. The fieldwork roles, the embodiment, the experiential understanding and the intellectual exploration all emanated from the dialogical inter-somatic play in the gym. Magnus' body was continually incorporated and combined with the fighter's existing somatic understanding and, as such, his MMA fighter's body was invented and continuously reinvented.

A body which is stained by violence can become pure and codified through another body's impressions on it (Kristeva 1982). Hence, Magnus was literally practicing his bodymind while fighting, since he was both experiencing a state of embodiment and producing results that could underscore the meaning of bodily experience.

We assert that when the focus of the researcher's project is embodied activity, in which he or she is operating in body and mind, pain can make explicit what the self-reflexive inner sensibleness between experience and knowledge is (Goodall 2008). The ethnographic embodied partnership, or "contract" between the participants and the ethnographer, is an inversion of the hierarchical relationship between teacher and apprentice (Goodall 2008, 11). The "scientist" had the verbal knowledge of academic speech and the means of analysis, whereas the participants had skilled bodily knowledge (Bar-On Cohen 2009).

However, the ethnographer was also a participant, and "they" were the observers of his practice (Bar-On Cohen 2009, 176). As Culbertson (1995) notes in her analysis of embodied transcendence, in the re-establishing of the self in the embodied field it is easy to lose sight of the body's perspective. The line between observer and the observed, then, is blurred, especially when our bodies are in the continuous process of actions and movement. By analyzing the ethnographers own body/pain, the method of somatic interactions as a corporeal tool became vital as it allowed us to discover the embodied phenomena of cultural constructions existing in MMA.

\section{Mixed Martial Arts - Pankration and the UFC}

MMA is a full-contact combat sport founded in 1993 and currently called Ultimate Fighting Championship (UFC) (Gentry 2011, 3). ${ }^{1}$ MMA is associated with an ancient fighting style that stems from a form of unarmed combat called Pankration, a Greek word made up of "pan" and "kratos", meaning "all" and "powers," respectively. Pankration has its roots back in 648 BC when Pankration was featured at the $33^{\text {rd }}$ Olympiad (Buse 2006). MMA matches include "two contestants wearing only trunks, small gloves and a mouth guard in a cage, and

\footnotetext{
${ }^{1}$ The Brazilian Gracie family instigated the first UFC event. They wanted to prove that their jiu-jutsu techniques were superior to all other martial arts specialties (Gentry 2005, 43). Roycie Gracie was the family's representative fighter at UFC 1, and he won it as well as UFC 2 and 4. Roycie Gracie's success revolutionized MMA by combining grappling and cross training. The Gracie family proved their Brazilian style of grappling techniques to be vital to MMA.
} 
unleashes a multitude of full force punches, elbow strikes, knee strikes, kicks, stomps, neck chokes, body throws and other grappling techniques against each other" (Buse 2006, 169). Victory is achieved by concussing an opponent by various means (Arvanitis 2003; Buse 2006). Recently the UFC has experienced dramatic growth worldwide, having globalized into a social movement in the martial arts industry (Abramson and Modzelewski 2010; Gentry 2011).

\section{Autoethnography and Participant Observation}

For this paper, we applied a qualitative analysis of MMA practice. Magnus informed all fighters at the gym that he was studying MMA. He collected data by both writing and taking visual field-notes. He also let the sparring partners have a look at the field-notes, thus making them more than mere "informants". Interviews often took place spontaneously, and in line with the recommendations of Gubrium and Holstein (2002), Magnus checked back with participants' opinions on the material.

Magnus performed the preliminary data analysis at his office at the university, transcribing interviews and organizing and keeping them in separate folders. This system, which included a secure CAT (Coding Analysis Toolkit), allowed him to compare the field notes with the data derived from the videos (including more than 40 hours of MMA practice) and audiotapes.

The fieldwork started by "classical" participant observation methodology, but soon a more autoethnographic research methodology was used (Denzin, 2003, 14). Feeling the punches and experiencing the drills and grappling as they affected Magnus' own corporal being, his autoethnographic contact with the fighters made the MMA experience more direct. Being "in-between", and concurrently learning about his body and how to master the violence and its effects, reformed his thinking as well as his bodily experience, shifting knowledge (Messner 1990). Later on we started to analyze the ethnographic fieldwork data from a phenomenological perspective ${ }^{2}$ as well as through the lens of a mixed martial artist's reality by reflecting on fighting as an explicit act of doing performance ethnography (Denzin 2003, 15; 2006; Atkinson 2006).

Magnus was an MMA student for twenty months at this particular gym. Eighteen participants were interviewed through spontaneous conversations, and the eight semistructured interviews focused on many of the issues regarding anger, violence, adrenalinerushes, and risk-takings related to MMA. An expanded semi-structured interview was conducted with two MMA instructors and two fighters who had professional MMA records, focusing on their teaching strategies concerning their club fighters and him. Pseudonyms were assigned to all interviewees.

Throughout the research period, we changed our initially biased perception of MMA as a sport involving violent actions. We came to see those actions as performative through the ethnographers' "lived experience" of violence, and did so to such an extent that we eventually took phenomenology as synonymous with lived experience (Csordas and Katz 2003). We also came to accept the view that critical and performative phenomenology is particularly adept at speaking to themes of embodiment in MMA fighting, as per the philosophy of Merleau-Ponty

\footnotetext{
${ }^{2}$ The phenomenological perspective helps us to understand how MMA bodies adapt to the hard training, as phenomenology shows us how bodies sense the milieu they are a part of and use that to build on the experience. By applying this perspective, we could break down the split between object and subject and reach the inner emotional spirit, the feelings of abject (the soul, the 'fighting heart' of the athletes) from the empirical findings, rather than scratch the surface of ethnography from an instrumental picture in which MMA fighters are stereotyped as only wild or dangerous sportsmen/women. We assert that this perspective vital to understanding MMA. If one attempts to read and interpret MMA fighting without taking into account the body's relation to the spatial experience, one likely will not get the quality of empirical data necessary to give a nuanced picture of MMA and instead continue to perpetuate an unfair picture of the MMA milieu.
} 
$(1964 ; 2002){ }^{3}$ Through this approach, our study utilizes emergent literature on methodology that specifically applies bodily and phenomenological theories as guides to explore issues of embodiment, time and space (see Csordas 2003; Csordas and Katz 2003; Denzin 2003).

As researchers and as researcher/participant, we use a dual-perspective ethnographical method that contrasts the tacit knowledge of embodiment with the explicit knowledge of an autoethnographic method. This allowed us to be able to reflect on the opportunities and possibilities of doing bodily "auto-phenomenological" fieldwork as a very physical activity "where words compared to movement become in a way relatively unimportant" (Bar-On Cohen 2006). In our reflections, we make use of recent works on embodiment (see Pagis 2010) and on silent meditation ethnography.

In addition, we utilized the approaches to autoethnography as a methodology for "personal" commitment and interest (Sparkes 2000; Holt 2003), and narrative inquiry (Olsen 2008), as well as Atkinson's argument on combining ethnography with participants (Atkinson 2006) and Denzin's autobiographical approach (Denzin 2006), both on "performance ethnography." Inspired by these researchers, we used a researcher/participant's autoethnographical story to include knowledge about a certain cultural phenomenon by bringing together Magnus' past and current field-site experiences into a narrative alongside those of the participants, to highlight the concept of performative acceptance.

\section{Aim and Purpose - Understanding Stained-Violence and Abjection}

The purpose of this study is to explore the experience of MMA from an insider's perspective and what MMA fighting means to us as researchers, with reference to the concept of stainedviolence on bodies. Stained-violence is a term we have adopted from Douglas's work on pollution (2002) and Minge's work on embodied fusion (Douglas 2002; Minge 2007, 252)

Firstly, Magnus utilized his own body to experience the physical actions involved in the sport, in order for us to be able to scrutinize how inter-subjective body-based ${ }^{4}$ research can support personified fieldwork. Secondly, we developed a deeper understanding of MMA fighting by combining the empirical data from the fieldwork with the painful outcome of the suffering body stemming from an autoethnographical story, and by describing our understandings of bodily force and extreme powers of kicks, wrestling and strikes inside the gym. $^{5}$

Thus the fieldwork has allowed us to set up a framework for how full-contact fighting can allow one to transform, transgress and internalize bodily violence based on the concept of abjection. Abjection is, literally, "the state of being a cast off." Applied in the MMA context, abjection means that fighters' narratives of their bodily experiences are often centered on the emotions they feel while giving and receiving pain, and the ambivalent feelings they share about using instrumental violence. We adopted it from The Power of Horror (Kristeva 1982)

\footnotetext{
${ }^{3}$ We argue that a dual-perspective ethnographical method, combining overt participation and autoethnography (telling the researcher's story together with the participants' experiences) in order to be both there and "in between there," can produce sensuous ethnographical knowledge that will offer a truer and more nuanced elucidation of what MMA fighting involves. Such a double-edged perspective makes use of a reflexive "inbetween-ness" dialogue, and generates different insights, not only about gender and MMA but also about the kind of discernments that are relevant to any embodied activity. Good fieldwork depends on tough-minded, critical reflexivity (Bar-On Cohen 2009; Davies 2004).

${ }^{4}$ In doing intersubjective body research, we apply the embodied and intersubjective focus of our research as the embedded territories of where the actions started and ended by learning the drills, routines and the lifestyle of an MMA practitioner. The researcher was in the MMA milieu to discover the role of the body in shaping its possibilities within the MMA system. From there it was possible to decode the subjective impact of MMA.

${ }^{5}$ We made use of the transparent, autoethnographic experience to gain a first-hand understanding of MMA, to grasp its underlying intricacies, and thus try to avoid any assumptions or generalizations in the ethnographic field data.
} 
and Creeds' work on "horror" (Creed 2009). We use it to describe fighters becoming ritualized and vacillating between two psychological states while fighting; the omnipotent take on violence and simultaneously controlling the aggression, the fear and the brute force they apply. ${ }^{6}$ We assert that there is a connection between the pain and stained violence that accompanies the use of brute force and that shapes the body through fighting in MMA, which we conceptualize as a body's abject that a successful fighter has to learn to handle.

\section{Towards an Embodied and Gendered Approach}

Many scholars of MMA emphasize its various masculine aspects (Bousfield, 2009; Hirose and Kei-ho Pih 2010). Bousfield asserts that the ideology of hegemonic masculinity is connected to militant gendered norms and that the performances of gender in the UFC are specifically coded in such a way to maintain and "resist critique by adopting a unitary purpose, the production of an extreme militant masculinity" (Bousfield 2009, 2). Hirose and Kei-ho Pih $(2010,4)$ argue that gender and sociality in MMA are closed boundaries within hegemonic and marginalized forms of masculinity, and are much more interactive than oppositional.

Others have looked at how MMA fosters the upholding of fear and managing emotional manhood (Vaccaro et al. 2011). We have definitely experienced how masculine norms are adopted and practiced in MMA gyms (c.f. Russell 1992). In recent years, the "confluence of interests amid the UFC and the American Armed Forces has produced an increasing link between efforts as the militant masculinities of MMA are employed to re-masculinize the popular perception of military" (Bousfield 2009, 2).

However, we believe it is fruitful to widen the debate on MMA and its complexity to gain a more nuanced perspective. We stress that MMA needs to be scrutinized from the embodied, inside and sensuous perspectives in order to understand more fully what is going on within its culture. While Spencer's research on participant ethnography and phenomenology $(2009 ; 2012 ; 2013)$ emphasizes MMA from a social perspective, he did not examine what happens "in-between" the fighting bodies. He merely advocates how MMA practitioners use, develop and master bodily techniques (Spencer 2009; 2012). By explaining how academic researchers of combat sports have outlined and debated masculinity, he emphasizes the hegemonic masculinity "which expresses certain emotions that signifies weakness and is devalued, whereas emotional detachment signifies strength and is valued" (Spencer 2012, 115). In a study of Kung Fu practice in the participant observation context, the authors elaborate on the concept of the "internally differentiated relationship" between human embodiment and forms of sociality (Jennings, Brown and Sparks 2010, 548), which advance forms of bodily sociality and that are characterized by a "recovered sensuousness".

We assert that MMA can also be a system of reciprocal and "embodied forms of sociality, constructed and reproduced through a violent order with the use of an explicit body on hand" (Crossley 2012). Our research supports the existence of this sensuous system, as the violent movements learned in the drills and the intensive tempo of sparring and training produce an extreme bodily situation where one has to guard one's body from attack while at the same time to attack the opponent.

While, superficially, learning street-oriented self-defense skills typify the world of the profane, a closer scrutiny reveals that, paradoxically, "real street combat is a highly sensual form of sociality even though its motives, means and outcomes can be extremely shocking and unpleasant" (Jennings et al. 2010, 548). We theorize that MMA utilizes some explicit

\footnotetext{
${ }^{6}$ The notion of "abject" stems from William Apes' work on life among the Native American Pequot People during the $19^{\text {th }}$ century. He found that members of the tribes through initiation rites became "cast out", alienated and put in extreme danger during liminal contexts outside of society norms (O'Connell 1997). Kristeva's notion of abjection is in this sense models how anthropologists have looked upon the safeguarding of a clean and proper body, which is made into a territory of borders (Kristeva 1982, 71).
} 
simulacra of mock fighting and assert that MMA fights offer the potential to, over time, transform this embodied art form into a profane process that reflects "real fighting" performed in a safe milieu (Jennings et al. 2010, 548; Sánchez García and Malcolm 2010).

\section{The Process of Embodiment}

MMA is composed of emotions, senses, movements, rhythms and corporeal intersubjectivity (Crossley 1996). Learning to master this sport is complex, as it involves submersing oneself in an entire cosmology of cognizance to become totally "in tune" with the body in the flowmode. Embodying the practice and finally becoming an MMA fighter depends on the endless corporeal repetitions of somatic understanding. Switching on and off one's "autopilot" of double consciousness - of inner and outer perceptions - may be a precipitous key, and one of vital importance, in this physically demanding process. Double consciousness is made possible through repetition and automatized movements of rehearsed violence:

Violence for me is not associated with my body. Training MMA has taught me how to handle force and to control it with my body. It is just there in me. I don't have to think of it anymore. It just comes naturally to me. (Marcus, UFC fighter)

Marcus's description of how his bodily process is consolidating violence "abjectively" shows that he has learned to shape his body through training. He restrains his tendency toward violence, changes its course, and chooses how to adjust and apply the force he uses while fighting. In a sense, he is in the "back" off his body, coping with violent impact by controlling his body and mind (Gentry 2005).

Martial arts historian Michael Poliakoff $(1995,23)$ argues that the body is a phenomenon with the potential for transformation when one is actively engaging in a role, in a process and in a movement. Thus, this transformation is something beyond the body itself. It is realized, on the one hand, by repeating movements until they become spontaneous (autotelic) and intuitive and, on the other, by learning how to keep emotions in check. In this situation, a tactic (e.g. a particular MMA position) and a conscious mental reaction to a situation (e.g. striving for survival in the ring) combine to become a somatic activity that can automatically also be detected by the opponent. When one becomes attuned to and learns these intervals of repetition within the body, the body-self can change.

Michael, one of the really talented fighters in the gym, came up to Magnus one day and said:

You know what? Just be natural with your body, and do it. That's the way to do it around here, just be natural with your body. Then you learn how to really change things with your fists, your breathing, your mind and the whole body...

In this study, we offer an evaluative methodology for autoethnography by referring to the body as a site of scholarly awareness and corporeal perception. Engaging in autoethnography can make the researcher intensely conscious of how he witnesses his own embedded formation of body experience. Subsequently, while fighting, he can rely only on the use and the suffering of the body. In Magnus' discussions with the participants about the embodied process of becoming fighters, they often referred to their own or others' bodies. Pain was a common topic, giving rise to comments such as, "I wonder what a rear-choke hold feels like", or "I was really beaten up last time after our training session", or "I feel I have more control over my body now than before I started my MMA training", or "I will choke him out and I know it will really feel bad", or "I am actually scared in the octagon", and "I feel horror before and after fights". 
To emphasize the emotional aspect of fighting and the dichotomy between body and mind, we refer to the MMA fighters' control of embodied habitus, which they did by managing the somatic abjection in their bodies and in their senses. While practicing, they were using a significant somatic self that we define as sentiments and sensibilities of perceptions that are both simultaneously a part of and a consequence of a stained violent bodily impact.

\section{Ambiguous Bodies}

Can the abject be inside, or perhaps it is outside, the body? How can one feel where, in the body, violence is located (surely we can locate physical pain)? What exactly is the experiencing of human malicious force? Is stained-violence between bodies an embodied spatiality, or is pain and suffering just a psychological and spiritual martial arts phenomenon?

The body, according to Maurice Merleau-Ponty (2002), is the vehicle for perception. It enables discernment of objects in its environment through the process of objectification. Pain, pleasure and suffering intervene in mind and soul via MMA training. Therefore, our autoethnography focuses on the intersubjective experience of feeling the pain and pleasure running through one's hurt and stained body "as opposed to only the beliefs and practices of the participants and others" (Denzin 2006; Meneley and Young 2005).

Bodies are ambiguous at the MMA gym, as they are subject to the human production of meaning through the threat of getting damaged, broken, punctuated and then subject to becoming a newly reconstituted body after the fight is over (see Crossley 2005).

Magnus, the ethnographer, had to gain control over his body through the rigorous training. To be successful in this fieldwork, he needed a fit, powerful body. This study is therefore an account of a constant transformation, an intersubjective engagement of the "to" and "from" through MMA. Ultimately the researcher became a floating "trixter", being neither here nor there, with just his body surviving in the ring (Zarilli 2009). He became a source of selfreflective duality of knowledge, and achieved an understanding of a bodily building process through an inside and sensuous perspective (Wacquant 2004b, 59).

In this process, the body became Merleau-Ponty's "lived" body, in order to be able to understand fighters' willing embrace of and submission to the pain and the rigors of the sport, which were absorbed "together" corporeally (Crossley 2005; Wacquant, 1995a: 88).

To cope with the challenges of MMA training/fighting, practitioners learn to transform their inner and outer bodies. ${ }^{7}$ In order to explain the process of alteration, the ethnographer examined his own, and his participants', bodily reformation. This transformation was primarily carried out by incorporating the body into a "double consciousness". 8

After the fieldwork we two authors of this article have together reflected upon the represented and intersubjective progression of the experiences of using violence in fighting actions, to come to an understanding of the "horrified abjection" that became a part of this transformation as a participant researcher. We stress that psychophysical training must focus not only on oneself as a doer, but equally should engage each individual in a training that is intersubjective. In this intersubjective space "between" and "betwixt", one can begin to attune

\footnotetext{
7 Inner body refers to the emotional impact of the brute harm absorbed by the body, and the external impact of the body is the physical collision fighters experience.

${ }^{8}$ Double consciousness is a term coined by W.E.B. Du Bois (1994) that refers to his theory of African American "double consciousness". The term originally referred to the psychological challenge of reconciling an African heritage with a European upbringing and education. Applied in this study, it means that a fighter similarly, but yet differently, needs to see him or herself through the eyes of the other fighter violently. "It is a peculiar sensation, this double-consciousness, this sense of always looking at one-self through the eyes of others, of measuring one's soul by the tape of a world that looks on" (Du Bois 1994, 3).
} 
one's body and mind to any type of "other," which are things in the environment such as the performance score, other fighters and even the spectators.

While executing the techniques, fighters learn to perceive their embodied actions from the outside. By doing so, they are able to react intuitively to the actions and the movements of their opponents autotelically ${ }^{9}$ (Spencer 2012, 91). This causes the outcast, in "between $\mathrm{n}$ betwixt" positions of being an athlete (see Turner 1969), to be a part of the contradictions of the double aimed and simultaneous activity of MMA; namely controlled chaos and limited and scripted violence (Green 2011).

In addition to the use of "double consciousness", we will show how fighters make use of an abject and stained body to adjust to the myriad effects of human force by them and on them. ${ }^{10}$ Collectively, the triumvirate of autotelic, liminal and double consciousness is the key to understanding how one's "single aimed" body shifts into a "double aimed" body that becomes a double consciousness (Du Bois 1994) in order to handle kicks, strikes, punches and pain. $^{11}$

\section{Controlled Violence}

Standing in the gym on the first day, Magnus realized that this was a place where he would learn how to handle and use his physical powers, perceived as Merleau-Ponty's (2002) "habituated actions," taking place while learning the fighting drills. Commentators on MMA have emphasized "the presupposition that violence is a "natural' proclivity of humanity, as it inheres in 'human nature' and it is a requisite to the maintenance of community" (Spencer 2012 , 115). One of the detractors' main concerns about violence in combat sports is the prevalence of brawls of rage, in which forms of aggression are chosen for the intentional destruction of the opponent. In Spencer's $(2012 ; 2013)$ phenomenological work on violence and Ultimate Fighting, he posits that certain rules are instituted to encourage rational forms of violence. The fighter's body thereby becomes a violent weapon (Spencer 2009, 119; 2013).

The controlled and limited violence in the actions of MMA participants works as a paradox in that Ultimate Fighting, when it first started, had (and still appears to outsiders to have) few rules. The contradictions of institutionalizing and normalizing supposedly emergent and unrestrained violent actions create an interesting tension between the ordered and the disordered; a central theme of this study. The perceived violence in MMA is prepared in an instrumental milieu and under a rigorous apparatus of control. There is a judge, ringside referees and medical doctors. Through the prepared pre-game plan at the gym, violence is rehearsed, scripted and organized in advance. This mis-perceived "natural violence" is an act of pre-repetitions that is transported into the ring under strict rules. Thus, disorder and anarchy are avoided. Studying the apparent paradox in MMA, the simultaneous dealing with controlling violence and applying power onto the opponent, offers ways to generate new theoretical insights.

\footnotetext{
${ }^{9}$ Autotelic means to condition the body to react automatically through training, by teaching the body to react efficiently and effectively to any attack.

${ }^{10}$ Stained violence is a term that we use to describe how physical actions run from one body to another continuously, and how this stained violence fills up fighters' bodies with power and force. Fighters learn to deal with and transfer stained violence to and from their opponents.

11 The media often describes the violence in MMA as "primitive" and "wild" (Ferrari 2013, 277). Contrary to that description, we look at MMA violence as "somatic codes of abjection", in which a fighter transgresses and adjusts their corporeal consciousness and self-awareness in relation to the violent impacts taking place against the body. Here the abjection of the internal body disciplines and controls the stained violence of the fighting and is used to subdue external pain.
} 
For example, Magnus could sense that MMA training teaches enormous control over both mind and body, and came to feel a new materiality of body and mind written all over his being as a person, researcher and MMA apprentice through the use of his bodily experience of full contact. The training changed his body in a way similar to what Csordas (2003) describes as new "somatic modes of attention."

\section{Facing Full-Contact Fighting}

Finally, after many training sessions, it was time for the ethnographer to experience "real" MMA fighting - and now we let him tell about this experience in the first person.

It felt surreal to stand there in the ring. My opponent, Thomas, and I were allowed to hit, kick, strike, grapple, and choke each other in three 5-minute rounds. I was wearing only my shorts, a mouth guard, and gloves.

I knew that I had the basic skills to do this, but I started to feel my insecurity rise while standing in my corner awaiting the signal to start. My legs and fists were shaking, and I lived through everything in slow motion. David asked me, "Are you ready?" My opponent and I touched gloves in the middle of the ring. "Ding!" The bell rang and we got started. "Let's get it on!" screamed David, and then he laughed out loud. For a split second I just stood there like a fool, staring at Thomas, who ran towards me and grabbed me around the waist, folding me to the ground.

The embodied experience was initially overwhelming. Was this real or was it just merely a sportive instance of practice that Thomas and I were engaged in? Inwardly, I felt uncertain and confused. I could not keep the different feelings arising in me apart from each other. My back hurt, so I told Thomas to "cool it". He stopped for a split second and then mumbled in my ear, "What's the problem?" This question triggered anger in me, and with enormous strength I managed to roll over on top of him and started to punch furiously.

To the untrained observer, MMA fighting might appear to be chaotic violence. Yet fighters themselves refer to fights as scripted, since sportive motifs involve planning out and rehearsing combat fighting (Van Bottenburg and Heilbron 2010). However, the fights are only scripted to a certain extent, as they are competitive events. Therefore, an important part of the preparation is to rehearse how to continuously adjust the embodied script to the opponent as well as the participating audience. And, it is important to acquire emotional control and learn how to manage anxiety and fear. To be disciplined and to evoke a sense of safety, individuals as well as the collective construct their embodied subjectivities and develop game plans that involve all these aspects (Cheever 2009). Moreover scripted fighting often elicits a kind of rough-and-tumble play, a form of aggression that in fact produces both pleasure and fear (Cheever 2009: 3).

By this time, my body was shaking with exhaustion, but I continued to successfully defend myself. Thomas suddenly shifted his tactics to grappling to finish me. To counter, I used my legs and thighs while lying on my back in a 'butterfly guard', holding him away so that he wouldn't reach my face. He hit and kicked my legs while searching for an opening. Then, David yelled out, "Stop!"

Round one was over. I sat down in the corner with my excited body shivering. I sipped some water while listening to David's coaching. "Breathe, take a deep breath; breathe." David told me that Thomas had won round one, and that I now had to make sure that it would be a standing fight from then on. 
As previously mentioned, fighters develop game plans based on a tactical framework. This includes rehearsing the body, the mind and verbal speech. Outlining the possibilities of the unpredictable directions of the fight is just as important as a game plan, since it is used to frame a performance that is attuned to one's strengths and the weaknesses of the other fighter. Fighters regularly embody this intentional preparation, and the utility of gathering bodily knowledge is vital for success.

Round two started with me holding Thomas at striking distance with my right fist. I moved constantly to the right, circling him, as my coach and I had rehearsed. We felt this would open up possibilities for me to strike with my left fist and kick with my left foot. At the same time, Thomas was jabbing with his left hand, which made it difficult for me to find an opening. I then threw a left kick, to distract Thomas, followed by a right jumping knee straight toward his solar plexus. I missed with the knee and Thomas countered with several strikes to my stomach and head. Strangely, I didn't feel any pain even though Thomas had landed two perfect strikes, because my adrenaline was rushing.

While we were hitting each other, I was aware of the sense that no violence was being done to me, and at that point my embodied experience occurred. I was both in there and not. (Incidentally, I also felt disembodiment later while writing about this experience.) I then tried to throw a spinning left kick to his liver but missed, and I became aware of just how hard it was to land a perfect hit onto Thomas's moving body. Round two ended.

Sitting on the stool in my corner and having a hard time breathing, my mouth guard was annoying me, my legs were shaking, and my arms felt like jelly. I find it very difficult to describe to someone who hasn't experienced a full-contact fight the feelings of power and the adrenaline rush that rushed through my body.

\section{The Culture of Embodied Sacrifice}

The immersed embodiments involved in full-contact fighting and the ever-present danger of being harmed tend to separate the body from the mind (Buse 2006). The reconnection of the two can be achieved through practice, which should involve generating awareness of the double consciousness of the inner and outer somatic mechanisms.

Through the experience of enduring violent attacks, a vulnerable body can be cultivated to the point of being able to canalize pain and become an armament (Milton 2004). I felt on an emotional level that my body was being absorbed by the milieu. I felt the strikes and I could handle the pain, as I was also filled with pleasure while getting hit. My thoughts were uplifted with joy, an adrenaline rush and an urge to keep fighting. Nevertheless, by increasing my awareness of this affirmation of the ongoing violent impacts on the body, the brute force inflicted thereby became stained violence that could both generate and mitigate the key elements of a double consciousness that could unify body and mind.

My experience in pain and pleasure, and my getting "turned on" by the use of my interfaced body, allowed me to discover that the instrumental somatic capabilities of fighting puts MMA in a recursive role. It is the use of liminal action, the abjectification that allows one to be disembodied from the painful impact. In a fighting situation, one has to complement the outer violent force with the inner understanding of how to transform the pain so that the violence doesn't become hurtful. Paradoxically, in the end not only the bodily defenses but also the mental defenses turn the stained violence into a weapon of resistance.

The sacrifices of the body, the paradox of surviving full-contact fighting and the challenge of avoiding getting beaten up also include managing others' bodies. Scripting and framing the body well in advance are important in that they can mitigate the danger to the body in a fight. Prefighting violent acts, meaning choreographing the violence in advance and thereby finding rationality in the liminal, generates and preserves resources for managing the possible outcomes of fighting. On this point, the participants often said that having a prefight 
understanding and a game plan in advance, and applying a mind over body scheme, made them feel secure. This was also true for me, as I personally felt safe by relying on the game plan that had been settled on well ahead of my fight against Thomas. When I interviewed Thomas after our fight, he stressed that he had also made a game plan.

\begin{abstract}
I was very nervous, and I had to go through my physical state as well as my mental preparation over and over again. I had my game plan and I was going to try to wrestle you down. disgusted by the amount of our violence. In the gym, a lot of time is devoted to build up this game plan in advance, trying to figure out the tactical mindset before entering the cage. I always put a lot of effort in getting the right picture of my opponent before an upcoming fight.
\end{abstract}

Four main aspects were included in our MMA fight: body, pain, practice and mind. There is a fine line between exercise and survival in the ring when these are put together. They are hybridized, and the violence is enhanced in such a way so as to become something else, which differs from exercising violence in the gym. When the exercise was emancipated from its locality in the gym, Thomas and I became impermanent and fluid sacrificial objects, where our bodies explicitly were the victimized subjects of violence as we agreed in a consensual pact to let our bodies clash. But by doing so, both of us temporarily sacrificed our objective bodies by embodying the omnipotent outcome of violence, as we battled to reinstate our bodies in the chaotic and controlled bout (Bar-On Cohen 2009).

Thus, we were in a process of framing our MMA bodies to be able to perceive them as proceeding from violence. In this way of looking at it, violence is not permanent within our bodies; it is decided by the MMA rules, and separated from both our bodies. When we embody MMA, we switch from an ordinary body to that of an extraordinary body of violence. It was our bodies that allowed us this transition, and the performance of our attacks shifted to a "real" battle. In this mode, fighting also prevented us from engaging in a chaotic activity which could escalate into rage.

As Thomas and I were training and striving for "survival in the ring", we adapted our private bodies, ourselves and the intersubjective capacity of our violent exercise, so that they were aligned with the MMA conceptualization of fighting in that special space. Thomas's body was sacrificed to become an MMA fighter, and in this sense, with his body-being merged with mine in this activity, we ritualized the complementary parts (body and soul; the fighting heart and mind) that built a representation of battle through initiation, liminality, and reincorporation (Turner 1995).

Fighting therefore permitted us to switch back and forth between the object and the subject of our transformed body-beings, and identify with our controlled abject. We both feared physical injury, and we downplayed those inner feelings by focusing on the outer object of ourselves in order to be able to withstand the potential dangers of the violence. Thus, we were implicitly suppressing the otherness of the other's body. As fighters, we had learned to manage the interpersonally violent abject; to give up and sacrifice our interacting bodies (Merleau-Ponty 2002).

As well, we were performing by using our nonverbal habitus, and through this our bodies became enacted personas with violent appearances. In order to understand the cultural performance of a bodily sacrifice, it should be noted that violence is the determining factor in how our bodies are perceived by and integrated within MMA practice. Violence becomes deceptive, and transforms through movements into a representation of "real" fighting, or, a simulacrum of a "mock" fight (Sanchéz García and Malcolm 2010).

Actions in combat are pre-reflexive, or beyond thought (Spencer 2009; 2012, 129). Our bodies reacted intuitively to the strikes in the ways that we had been taught. By using the 
accumulation of pre-fighting scenarios, my game plan, I knew, and my body sensed, what strategy to embody. As Spencer writes, the reflecting on drills, drills and drills is applied, because the ever-changing nature of fighting makes it so unpredictable that fighters cannot reflect on their actions while fighting (Spencer 2012). That is, "the body senses what it is to do in a fight and reacts accordingly" (Spencer 2012, 91). In fact, fighters do this by uniting the past, present and future of the body (Merleau-Ponty 2002), in order to adopt a temporary "martyr" position and thus be able to strike back effectively. This is coached repeatedly so that the fighter can embody the tactical repositioning of strategies to exploit the opponent's weaknesses.

\section{Round Three}

Round three started. Thomas and I met in the middle of the ring and touched gloves. Remarkably, I did not feel afraid anymore. Thomas immediately threw his arms around my waist and pushed me up against the ropes, pressing his head under my chin, striking my stomach and using his knees to attack the sides of my thighs. I could hear what I thought was him breathing heavily, until I realized that it was my own breathing. I began holding him at a distance with my right elbow and using my knees to hit his thighs.

When we fought, "being in there" was a dreamlike experience; it was a flowing. I remembered, and my body remembered and recalled, something from within. Instead of resisting, I "danced" along with Thomas, and to my surprise it worked really well. When he attacked, I just tracked his movements and made use of my rhythm and the skills deep inside of me. Detecting bodily awareness, and with its superb rhythm and acrobatic influences, I avoided his takedown attempts. I managed to slip and slide from left to right and, following with my perfect left kick to Thomas's stomach, hit his liver. He went down in severe pain. I turned around to David and I cried out with joy - a kind of a primal scream.

Suddenly, it became totally silent in the gym. Mathias and Peter rushed in to help Thomas. But, I felt euphoric: "I won - I did, didn't I?" I asked David, who was looking at Thomas on the floor. No one seemed to take any notice of me. I suddenly realized that I had crossed a thin line. What I had perceived as violence when I was new to MMA fighting no longer appeared violent to me. Also, I did not feel afraid or horrified of what I had just done. Instead I was excited. I sat down next to Thomas, and asked if he was fine. As the adrenaline rush faded, I slowly came to my senses as Thomas nodded that he was OK. I felt that I had achieved something great, but felt very ambivalent toward what I had just done. Was this really OK? All at once, the abject came over me; disgust, horror, shame and delight at the same time (Vaccaro et al. 2011).

The battle, which had partly been choreographed as we had trained together in the same gym, is a cultural work of corpus modus (Spencer, 2009; 2012). These types of exchanges between bodies were modes that I had learned to discern while practicing fighting, and they were at the same time the modes that stigmatize fighting as violent. And, by way of the fluid abject that turns the outer object into that of a sensitive subject, the internal "pain" became the abject interface between Thomas and me and our experienced bodies. There was an embodied socialization that produces a particular way of being in the world, "which provides the basis of innovation that is necessary to embody fighting" (Spencer 2009, 133). But, most importantly, the initial emotion of being afraid had left me, and I was perfectly calm.

\section{A Dual Examination}

Back in the gym to continue the training, I can hear the instructor scream at me, "Come on, fight! Use your body to pull your opponent off!" After the first blow, I start crawling across the floor with one of my participants hanging on to my neck. Precipitously, I find myself analyzing the situation; my opponent, what I am doing, what my body is doing, and what his 
body is doing to me. I am trying to discern the impact of my corporeal understanding. I am collecting data with my body, and at the same time analyzing the somatic understanding of full-contact fighting.

These correlating "schemes of comparing, categorizing and correcting, iterating and thus learning from experiences," (Bar-On Cohen 2009) as codes of somatic integrated phenomenological collisions, are massive. I am in a classical dualistic thinking mode. I must sort things out through logical operations in order to confirm cognition. My senses are collecting ethnographic material while, at the same time, as I am fully aware of myself training. I struggle in real time to internalize the emotional effect and determine "what violence really is to be defined as" and how to make use of my inner cognizance.

I am again abruptly shocked into conscious awareness when my instructor presses his arm around my neck, strangling me, in a classical "rear choke-hold". I tap out. He says, "That's not too bad - well done. OK, go get some water." I can hardly breathe and I am very thirsty. My body is shaking and my muscles are tense. In the situation at hand, the instructor is rehearsing a kind of self-reflexive embodied logic. However, the implementation of this habitualized logic is purely physical and lasts only for objective fractions of a second, for me to try to grasp and acknowledge it. And, its practicality depends also on me interpreting the body as an undetailed whole.

One of my participants tells me that he can understand why many people feel disgusted or uncomfortable when they only watch the exchange of brutal force from the outside. He is addressing the fine line between what spectators experience as violent and the physical control that has been meticulously rehearsed by the fighters. What the abject does for the fighter is to regulate and balance these two. In doing so, the abject manages to connect object and subject. In the game and play of full contact martial arts fighting, abject keeps these two parts in place. Sheridan, a former fighter and a popular writer, emphasizes that fighting is ninety percent a mind-game that includes learning to master the inner self to accomplish the necessary skills of cage-fighting and enduring the pain, which in turn includes locating an inner awareness (Sheridan 2007).

How do MMA fighters learn to intrinsically identify with these embodied activities? Sheridan (2010) asserts that one must first learn to acknowledge bodily inner self-awareness in order to understand the fighting body. These are somatic enigmas that MMA students must resolve in order to master MMA practice. At first they do not know how brute force is supposed to be handled because they cannot understand, and thus control, it in either their own body or in their opponents' bodies (Bar-On Cohen 2006). They must learn to link violence to an inner understanding of the self as they repeatedly practice in an effort to attain these skills, so that their bodies can be constructed anew (Bar-On Cohen 2006, 73). As UFC fighter John said:

Of course MMA hurts. It's painful. But I can control the force because the violence glides off my body when I attack my opponent. It is consent between my body, my opponent and me. Therefore it doesn't hurt.

By focusing on the body, one is aware of its premises and how it is arranged and constructed through the constant repetition of memorizing differences in, for example, controlling one's brutal power vs. executing MMA techniques efficiently and effectively. As Jim put it:

Man, if you don't know or remember your patterns when in the fight, like your body is an automatic machine, you're lost in there.

The body is created actively out of what it learns to discern and enact, and the body is also prepared actively from what it learns to do. Violence plays a key role here in that two 
fighters' bodies are entwined together, floating free in manifold positions that are never static, as each constantly works on enduring pain and controlling the violence of combat (Ching and Mayeda 2008). The meaning of this un-translated substance/abject in MMA training is a silent bodily phenomenon that needs to be managed by the fighter, and its practical use unfolds only through corporeal practice or during the experience of full-contact fighting. Rick, another sparring partner, explained:

Yes, I have it inside of me, my fighting-heart, right there on the button with me, performing the actions in the cage.

Consequently, fighters learn somatic understanding and transform themselves into bodies that are capable of giving and taking pain, to thereby endure the rigors of violent impacts (Downey 2007). This is partly done by executing bodily techniques through body callusing (Spencer 2009). However, it is in the repetition and the learning of bodily resistance that the MMA fighters form and re-form the somatic codes, causing the inner abject to be in a continual state of embodied fluidity, thus becoming (an instance of) autotelic tacit knowledge (Spencer 2012). Mike talked about fighting as a floating, violent and continuous process:

To me, fighting is a constant process where I learn to handle force, to find ways to master my understanding of violence and how these powers that my body absorbs can be maximized in order for me to attack my opponent's body.

Sheridan (2007) emphasizes this importance of developing an inner control of violence as part of a self-aware reflexivity. The concept of brutal and violent forces stipulates that MMA fighters must identify the somatic elements of their continually embodied abject in order not to "split up" their intersubjective omnipresence. Fighters learn to direct force and power as tools for obtaining a good relaxed stance, keeping the opponent at distance, jabbing and doing reflexive punches. Thomas explained that:

the drills have to be in the backbone, right there with you, with having to think, just strike and then back again defending and back in punching, striking, and then out of reach, forth and back.

\section{Performance Decryption - Finding the Fighter Within}

In our common analysis we find that the somatic hidden "abject" is designated as an undefined entity that is actualized through somatic participation. Hence, the fluid process of exchanging bodily strikes creates a narrow line of passage from my sensed social data to thought, and then to action; from body to mind and back again. The strikes emanate from the internalized understanding of the MMA practice as instilling a somatic meaning of the bodyself and the potentialities of using violence. The connections of the feet to muscle, eyes to ears and fists to emotions blend with perception and self-perception, fusing somatic abjection and emotional balance into one (Bar-On Cohen 2009).

The existence of "pain" is channeled into an embodied movement, in the initial state of fighting, from where you actually fear for your body - or even your life. Turning this fusion of different corporeal experiences into a clash of hybridization is an intricate, culturally transmitted and intersubjective practice (Crossley 1996). It is a physical capability, learned and revealed through interaction. Yet, the pain was scaring and, sensing the potentiality of violence, horrifying by that potentiality.

Likewise, the world of MMA is a complex set of bodies. We initially perceived it as an explicitly violent and harsh milieu. But, as the body-self begins to collect experiences and becomes aware, switching between being aware of itself and the objects it perceives, a gap between the horizon of being and its sensible perception grows. This growing gap between 
this awareness of the body as a tool of perception and that of the outside world of objects, this sublime process of subjectivity, includes the objectification of the body itself by making it an object among subjects.

Thus, the body itself has a double identity. As the first tool of perception, it is at the extremity of a person's objectified world and on the horizon of one's awareness of being human. But, the body is simultaneously in the world as a discernable object within the horizon of being merely a representation, since the body can be looked at from an outside, objective point of view. Therefore, the abjection is there in the middle of this gap, managing the ambivalent impact of violence by means of a double consciousness.

The special treatment that Magnus received from the instructor named Chris was perhaps intended to help make him conscious of his own bodily self-reflexive awareness by recognizing that this treatment was a source of represented power from Chris and to push the fluidity of resources and volatility from within. So, what then is MMA violence in the body of the researcher? As already noted, the concept and the etymological substance of the word "violence" cannot be defined statically. Violent meaning is formed through experiencing viciousness. It is demonstrated, used and pointed to, but it is problematic to try to define "violence" in semantic words and devoid of the praxis of MMA training.

While this formulation of the innerness of the body during MMA training may be incomplete, we should realize in body and mind that violence is intersubjective and also is as much a characteristic of the body - everyone's body - as is breathing and moving. When Chris then refers to "natural" as "feel it", as something internal while fighting in the ring, it means that he has had an adrenaline charge, which is a somatic-emotional capability that, like other sensed and felt experiences, cannot be accounted for solely in words. He himself acknowledges that it's hard to explain.

Controlling emotions is not sufficient to somatically display the absence of sensations. For the display to be credible in an extreme emotional state in combat such as fear, anger and vengefulness, which we consider as part of the body, must be overcome and must cease to influence the anxiety fighters experience in their actions (Bar-On Cohen 2006). To do so demands diligent and sustained MMA training, and thus engaging in MMA practice can also be seen as an expressive endeavor in locating the hidden abject. In this context, emotion is a source of action, of volition. Therefore, the capacity to control this "violence", to hide it or to use it, is also the capacity to avoid the influence of sentiment in battle (Almeida 1986).

\section{A Mental Challenge}

In this study we use the phenomenological-inspired model of embodied activity as a livedthrough process in parallel with that of Kristeva's concept of abjection, for two main reasons. First, culture impresses upon the body a learning process that begins with affections and emotions. Second, the abject is an intimated, reproductive link between the subjectivities and the objectivities of the somatic world. According to Creed (2009), this means that the abject perspective makes us horrified about our own bodies and what is unnatural about them, so we simultaneously feel both disgust with and delighted by our bodily actions. MMA fighting is an extreme bodily as well as mental activity, the game of the soul (Wacquant 2004b), as fighters learn and adapt to the "unnaturalness" of finishing their opponents.

As a border between our inner abject and the outside world, violence defines but also disturbs our identity when we are confronted with this transformation (Creed 2009). Drawing on Creed' view, we assert that sense, rhythm and pain are aspects of a fighter's violent conduct. On this point, fighting is an expression of the audacity of the bodily viciousness and of the physical impacts of MMA that "autotelically" stain fighters' bodies, making the practitioners feel cast out and horrified at being at the borders of an abject liminality (Spencer $2012,117)$. The abject stance is essential for the construction of both inner and outer attitudes 
towards fighting and the body in action. Their way of sensing the "brute" force impact of punches is also fueled by sentiment, and this both leads and contributes to the enculturation of a strong disembodiment, where dual separation can eradicate pain.

Phenomenology offers a dynamic and fluid model for this abject stance as a "lived in process", constantly evolving as an effect of the interactions of fighters and their physical engagements. Kristeva's abject offers a theoretical model of fighters "sliding" the "floating" body in flow-mode, "because martial artists are performing an activity that is so extreme, which is why the concept is compatible with a phenomenological standpoint" (Csikszentmihalyi 2003, 73ff.). In this sense they are "in the "flow" within the sportive environment as athletic players.

\section{Somatic Abjects}

We stress that in thinking about the abject phenomenologically, we interpreted the data in order to analyze the corporeal mechanisms that change fighters by making them more comprehensive combatants. Hence, the term abject explains the philosophical embodiment of the structures that are the interior and exterior aspects of a bodily experience, where a practitioner ultimately "casts out" the body in an intense situation (see Wacquant 2004; Woodward 2008). Hereafter, we refer to corporeal signs such as punches, strikes, kicks, knees, armbars, elbows, ground and pounds, rear-necked chokes, whose "deciphering depends on somatic experience and whose meaning varies accordingly", as "somatic abjects" (c.f. Bar-On Cohen 2006).

Perceiving MMA fighting through the concept of abjection allows for a conceptualization of a theory of internal body dynamics which merges the perceptive sensitivities such as the rhythm, the drills, and the dancing and pulse of martial arts fighting. Thus, the somatic codes of abjection have the capacity to succinctly focus the fighter's awareness onto a certain aspect of bodily innerness (e.g. anger, lust, tempo, pleasure, pain, and rage, as well as emotions such as fear, guilt, shame and hate).

We use the concept of abject as an interface between the internal and the external positions of the body. Though it may be floating freely as a viscose model (the body is in this sense an adaptive receptor, adjusting to powerful and physical pressure - c.f. Van Bottenburg and Heilbron 2006), the body is also bruised. As Minge states, "floating freely" can also be described like this: "In the same moment, I am fluid and mobile, like water, I float, move my limbs" (Minge 2007, 252). This is similar to how the ethnographer in the field tried to manage and survive fighting, thereby decoding the somatic notion of pain, in the "stained body" where violence ultimately is transferred into another body.

Nonetheless, the notion of "violence" in MMA connotes an ambiguous meaning of both object and subject simultaneously. As violence moves through the body abjectively, "it forms itself to the shape of the body that holds it" (Minge 2007, 253). One is also instantaneously contained, stained by human force; objected and abjected, experiencing this violent contact subjectively, and filled with somatic fuel. Therefore, pain disperses, and "floats beyond the body into which it has molded" (Minge 2007, 252). Somatic abjections of fused force are neither "out there" nor "in here". They are both a part of the world of MMA practice and a part of the fighter, of the body as an intersected link. The ethnographer is as well a "cast out", studying the participants' bodies at the same time, as he is dependent on these very bodies while fighting with them.

Likewise, the participants are "cut out" in the borderlines of being examined while utilizing full-contact actions against the researcher in a "cutting edge" (Barad 2007). Most importantly, the participants are the targets of his physical actions that stain their bodies, as both parties are "semi members" of these combat exercises that take place (Wolcott 2004). Subsequently, they are neither here nor there, but everywhere with their interfaced bodies, and 
thus there is no clear boundary separating them as they endlessly stain each other with powerful force.

In another aspect, Kristeva (1982) states that abjection is an embodied condition, and that the body never really has been simply a static and complete subject performing actions. It always confers a potentially higher level of consciousness, compared to the surface of the bodily object. Henceforth, this body that she calls heterogeneous is both body and spirit. These parts are separated by human conditions, but the forceful conditions in MMA point to a "split body", a body made of spirit, mind, and soul (see Wacquant 2004b) that needs to be completely submersed in these actions in order to be reunited and become alive (Kristeva 1982, 113-25).

Drawing on Kristeva, we stress that bodies can become alive when they are submersed in powerful martial art actions in MMA fighting that attentively allow them to find a balance between the dichotomies of body and spirit, control and chaos, defense and attack, and discipline and emotions. For this reason, a fighter must balance between the outer force that is applied by others and the inner subjective experience of the influence of that force that is employed by oneself. As Kristeva body/mind relationship, and similar to Wacquant's (2004: 60) experience with boxing, the course of the researcher's training was mainly in understanding the embodiment of body techniques deployed. Nonetheless, it is the coming together of body and mind in this way that makes resisting pain and maneuvering bodily violence possible.

\section{Entwined Bodies}

Sharing the energy of fighting with the fellow participants opened up the awareness of a dynamic relationship; the exercise of bodily sequences of movement that are entwined together as they are performed (Sheridan 2010). The martial arts are based on movements transferred from one body to another, from one fighter to another (Bar-On Cohen 2009). As Eric, a professional UFC fighter, put it:

I am nothing but pure body when fighting. I am at the mercy of the body, but the body cannot function when performing without the movements that have also been repeated in my mind. I have to be like an autopilot in my head as well.

This exchange between body and mind, which is a somatic shift that constitutes the foundation of an internal understanding, turns violence into repetitive patterns of silent movements (Bar-On Cohen 2006). By blending and remolding the violent shaping of the body and mind while employing the outer space "outside the body", forceful practice is connected to fighting interaction and, as such, is obvious to everyone. The transparent opening of intersubjective space between fighters offers a context for fighters to begin to attune themselves to one another (Zarilli 2009, 94-95). Thus, in the combative context, the two fighters have the opportunity to share their embedded knowledge of MMA practice.

The intersubjective process of adjusting and sharing embodied knowledge is an open invitation construed to identify the "trixter" of the body as a silent abject, for the purpose of controlling the chaos of fighting (Zarilli 2009, 95). The forces that the fighters try to merge together during training are all based on close somatic violence that is translated into rehearsed situations and repeated exercises (Bar-On Cohen 2009, 154). As a result, the researcher as a fighter carries in his body the unresolved frictions, the emotional battles and the brutal outcomes of fighting in a new and mindful understanding that is fueled by an ambivalent, horrified posture.

How, then, can an extreme force such as violence be embodied in other martial art athletes and transferred between bodies? Moreover, how can the bodies become interactive with each other? When stained-violence slides from one body onto the opponent's, violence 
starts to circulate between them back and forth as they attack and defend themselves from each other. Amidst the fighting, pain constantly shifts what violence means and says about their bodily experience. Orienting towards deconstructing violence inside the moving body can be, for this reason, an ongoing and often long process that requires certain modes of attention as well as conditions for corporeal achievement. They are both tools of experience and of fighting action, as well as objects of a specific kind of corporeal logic.

\section{From Training to Fighting}

At the MMA gym, the mechanism of sense-making can be observed and the cultural understanding of violence and its connection to "the body" and "the perceptual" interaction are explicitly exposed. In our study we explored the carnal cultural interaction because, in these settings, intimate somatic violence is translated into taught and rehearsed circumstances and repeated exercises. The participating bodies created eruptive violence and framed it to changes in the course of the violence, so that it became something else, polluted, stained, and transmitted onto "another fighter" (Minge 2007). These pre-game plans of rehearsal made the ethnographer feel okay even though he was a bit terrified and traumatized by the deep and hard violence.

The inner abject, the audacity and the embodied mechanisms applied to handle pain are experienced through the possession of "brutal powers", which also means that fighters internalize shame, guilt, and the stigmas of their learned capacity to be violent (see Vaccaro et al. 2011). In the training, this potentiality was embedded in the bodies to create a change in understanding of the enactment of corporeal violence, as the fighters interfaced with both internal and external dimensions of embodiment.

Finding "the fighter within" requires one to deal with and possibly change preconceived notions about a violent body. MMA fighters constantly refer to this unspoken "inner capacity" to have control over guilt, pain and manhood simultaneously (Vaccaro et al. 2011, 425-31). In the interviews, the fighters often alluded to their energies, the strength of their powers, the building up of their stamina, and boosting themselves from within. By applying these sorts of coping and defense strategies, fighters can transform their feelings of being afraid, scared, and terrified before, during, and after a fight. For example, just before his fight, David said:

I must get angry. I need to get going now, without losing my temper. (Magnus asked him what he meant.) It's just that you can't be nervous, and start fighting like a "deadbeat" on the street. (OK, Magnus replied, what is that?) It's when you lose control of yourself and start to just wave all over the place with your fists.

Fighters emphasized this use of a highly coordinated and organized body. After losing fights, Magnus' training partners often blamed their performances on a lack of audacity, or on their bodies feeling unfit or out of control, or that they had not connected or interfaced with their inner energy. Fredrik explained:

It must have been my nerves - my body was out of order. I couldn't hit or strike properly. (Magnus asked him why.) I sort of felt like I kind of lost "it" - there was no energy from my body. It didn't answer my head.

Another fighter, Alexander, said, "It was super, my body was doing it for me." He implied that his body was "doing it" for him, almost automatically, and described his body being like an "airplane" moving forward and that his head did not have to control what his body was doing. What Alexander was suggesting was that his body had transformed into "an airplane on autopilot" and had become something that controlled itself without him having to guide it by constant thought and actions. This he referred to as having an "auto body". David had 
similar reflections before a fight. He thought that he must cease to master his body without losing control and energy.

Altogether, these approaches outline a difference between bodily actions and actions in the mind and the soul; between external awareness and the internal senses. They both seem to be important parts that need to be fused together "autotelically" (see Spencer 2012) so that a fighter can function effectively. In doing so, he or she makes use of a double consciousness while fighting.

\section{The Changing of a Bodily Habitus}

Becoming a mixed martial artist means that the fighter must embody the process of finding and adopting a strategy for and a tactical incorporation of a proprioceptive violent mind. The body must learn how to register what it has to do in a given combat situation. This is a progression that involves two different aspects. First, the actions that one engages in must be viewed as necessary constituents of a path of bodily transgressions. Second, one must work towards being "one" with the body in a flow-mode state while simultaneously being constantly mentally prepared to be able to adjust to the changes in the physical environment.

The progression is along a particular rite of passage, and the incorporation of the participants' bodies indicates a self-reflexive identity that outlines their intrusions, and the intrusions of others, into the field. Becoming aware of one's bodily dispositions, which become altered through the learning about the cultures of fighting, results in an ongoing transformation of identity. Entering the ring marks this rite of passage. A fighter becomes a mixed martial artist through his or her experience of being in the ring (Spencer 2009, 136).

At the beginning of the training, Magnus was impressed by the immense amount of physical exercise that frames an MMA workout. He had to completely reconstitute his bodily comprehension. Training to experience full-contact fighting is thus a reverse learning process. While a mixed martial artist must train in various martial styles, the training must begin with an empty body; one which is unhabituated toward violent conduct. The metamorphosis of the fighter follows the bodywork, and occurs slowly. Ultimately, every fighter's habitus changes. Each goes through a somatic creolization of what violence is to them, what it feels like and, significantly, what it is like to be violent. Thomas stated this after our fight:

You know, of course I wanted to win, with every possible means. I was prepared to finish you off with hard strikes, hoping to choke you, but I can admit that I would never have done this without taking MMA classes. It would have felt strange wanting to smash someone's face in.

Thomas touched on the process of passing through the cultural construction of MMA learning, illustrating that MMA fighting involves a system that is partly predetermined, as fighters' bodies are predisposed by their trained actions and changing bodily attitudes (Wacquant 1995; 2004).

Magnus' bodily battle with Thomas looked chaotic, validating that their training sessions had been open to the utilization of the violent interventions of the body. In this open system, "training is always scenario-based, often emulating actual combat situations" (Spencer 2009, 137). This supports our assertion that in order to be a mixed martial artist the bodily constitution must be capable of shifting from a controlled body to an uncontrolled somatic understanding of the body, and back again. The fighter has to imply "a specific body composition to withstand the rigors of the sport" (Spencer 2009).

In addition, Magnus had to acquire an effective body, derived from training that would allow him to be able to unleash controlled violence in combat. Hence, it was his acknowledgement of what the body could do to his opponent that tied the body to the mind, and vice versa. The process of training to be able to do this is twofold. First, the substantive purpose of the fighter's actions is presupposed by the fact that what a fighter's body does 
matters. Second, bodies are perceived to be affirmed in relation to violent conduct. The transfer from controlled to uncontrolled actions occurred when Magnus entered the ring, where the "real" action took place. It differs from the ordinary situation in the gym where the participants train as a group and learn the regimen of MMA fighting. The bodily phenomenological "identification" becomes an act that signifies participation in fighting, and the transformations of the body display the internal bodily characteristics. The outside, objective body is reformed through this inner embodiment of recognition of being an MMA fighter. The body tells a story of being a fighter and confirms this when, for example, Magnus' body was associated with kicking Thomas in the stomach. It is obvious that the ethnographer's recognition of himself as a fighter occurred through his body's actions and during the performance of his acts and intentions.

\section{Conclusion}

In this article, we have together explored the sensual elements of trying to grasp one's bodily understanding through MMA fighting. Becoming a mixed martial artist means learning violent yet resistant conduct. The fighters use their bodies to create eruptive situations of violence that are continuously reframed, in order to further the progression of that violence to the point that it becomes something else; under surveillance, disciplined and strategically controlled for its sportive purposes. Violence in MMA is, thus, paradoxically transformed. It is stained and soils the combatants while it simultaneously transgresses into a series of intersubjective, performative acts.

Due to the immense levels of violence and pain, fighters must be subject to a process we call "somatic abjection", whereby they see their bodies as sites of embodied action and forcefully seek, through the incorporation of a violent bodily utilization of pain, to strengthen their minds and senses. With the subsequent acquisition of an understanding of abjection, violence is enhanced and made into a resource of bodily power that is both brute force and, at the same time, controlled energy used to resist harm and endure pain. Through this process, MMA fighters can transition into acquiring a kind of double consciousness.

By engaging in embodied autoethnographical research, Magnus studied himself and others as MMA fighters. The process of his bodily fluctuations in trying to understand pain and violence, sense and rhythm, from day one in the gym until now, has been possible by using some important key functions.

It was made possible first by transforming the body, bit by bit, and thereby changing the "mind" of the researcher's body as well as his ambivalence toward violence. In fact, the bodily understanding changed as a result of the autotelic repetitions done in MMA training. The body was blurred in positions between the prefight preparation and the training, and these positions are utilized through pre-reflexive actions while engaging in full-contact fighting. The body was altered via a sensitive inner affirmation and was adapted to force; hence the body was capable of withstanding outer pain. The body itself was changed as new meanings, perceptions, and social inflictions developed where none existed before.

Second, through being subject to violence by engaging in the habituation process of practice, the researcher's somatic understanding shifted dramatically. Through embodied fighting, he repeatedly altered his earlier stances on the use of the brute force that is typical of MMA practice. In our common analysis we have come to understand that fighting another human being in a controlled and defined safe setting involves a process of overcoming the "delight and disgust" feeling of hurting someone, and also involves shifting bodily selfawareness. Game-planning the fight in advance transfers bodily ideas and changes previously held understandings of violence.

Third, the practice of mixed martial arts can entail profound transformations, because new conceptualizations of pain, violence and a "stained violent" body can be discovered and 
perfected. A highly trained consciousness of self-reflexivity is crucial to be able to acknowledge the bodily systems in learning the regimen of MMA fighting. Repetition is a way to experience, understand and control a forceful and violent body, and thus is part of the process of acquiring such a consciousness. Through repetition, mastery of the body and change in the somatic "being" may result, in the fighter's habitus, insofar as a new body is taught, trained, and exercised and then added to the body's pre-existing inner corpus.

Finally, through a mixture of phenomenological and performative decryptions of the body, our study has contributed to a broader exploration of how physical force, pain and violence are constructed in MMA fighting. With the understanding of abjection, violence can be transformed into a resource of bodily power that is simultaneously the brute force and controlled energy used to resist outer harm and pain in order to deal with suffering. Using the body as an instrument in decoding MMA fighting was made possible by seeing the participants as being in a continual state of progression.

In addition to its empirical and theoretical aims, this study contributes to the discussion about qualitative methods. Our standpoint is that due to Magnus' training in MMA it became possible to generate knowledge from personal experience. Through embodied autoethnography, we have emphasized the importance of ethnographical studies that are based on and depend on particular embodied methods and the narratives that explain them. Autoethnography offers a way to situate self-reflection within the research process by making the self the object of research and by developing a reflexive connection between the lives of the researcher and the participants.

\section{References}

Abramson, Corey and Darren Modzelewski. 2010. Caged Morality: Moral Worlds, Subculture, and Stratification among Middle-Class Cage-Fighters. Qualitative Sociology 34(1):143-75.

Almeida, B. 1986. Capoeira: A Brazilian Art Form. Berkeley, CA: North Atlantic Books.

Arvanitis, Jim. 2003. Pankration, the Traditional Greek Combat Sport and Modern Mixed Martial Arts. Colorado: Paladin Press.

Atkinson, Paul. 2006. Rescuing Autoethnography. Journal of Contemporary Ethnography 35(4):400-4.

Barad Karen. 2007. Meeting the Universe Halfway: Quantum Physics and the Entanglement of Matter and Meaning. Durham: Duke University Press.

Bar-On Cohen, Einat. 2006. Kime and the Moving Body: Somatic Codes in Japanese Martial Arts, Body \& Society 12(4):73-93.

Bar-On Cohen, Einat. 2009. Survival, an Israeli Ju Jutsu School of Martial Arts: Violence, Body, Practice and the National. Ethnography 10(2):153-83.

Bousfield, Dan. 2009. The Diplomacies of Ultimate Fighting: Resurgent Masculinities of Global Militancy, International Studies Association, $50^{\text {th }}$ Annual Convention, New York, $15^{\text {th }}$ of February, 1:(30)1-18.

Buse, G. J. 2006. No Hold Barred Sport Fighting: A 10-year review of Mixed Martial Arts Competitions. British Journal of Sports Medicine 40(2):169-72.

Cheever, Nancy. 2009. The Uses and Gratifications of Viewing Mixed Martial Arts, Journal of Sports Media 4(1):1-15.

Ching, E. David, and Mayeda, T. David. 2008. Fighting For Acceptance: Mixed Martial Artist and Violence in American Society. New York: IUniverse, Inc.

Creed, Barbara. 2009. The Monstrous Feminine - Film, Feminism, Psychoanalysis. London: Routledge. 
Crossley, Nick. 1996. Intersubjectivity - The Fabric of Social Becoming. London: Sage. Crossley, Nick. 2005. Mapping Reflexive Body Techniques: On Body Modification and Maintenance, Body \& Society 11(1):1-35.

Crossley, Nick. 2012. Towards Relational Sociology. London: Routledge.

Csikszentmihalyi, Mihaly. 2003. Good Business: Leadership, Flow, and the Making of Meaning. Basic Books, Inc.

Csordas, Thomas. 2003. Embodiment and Experience: The Existential Ground of Culture and Self. New York: Cambridge University Press.

Csordas, Thomas J, and Katz, Jack. 2003. Phenomenological Ethnography in Sociology and Anthropology. Ethnography 4(3):275-88.

Culbertson, Roberta. 1995. Embodied Memory, Transcendence, and Telling: Recounting Trauma, Re-establishing the Self. New Literary History 26(1):169-95.

Davies, Aull, Charlotte. 2004. Reflexive Ethnography - A Guide to Researching Selves and Others. London: Routledge.

Denzin, Norman. K. 2003. Performance Ethnography: Critical Pedagogy and the Politics of Culture. Thousand Oaks: Sage Publications.

Denzin, Norman. K. 2006. Analytical Autoethnography, or Déjà Vu all Over Again. Journal of Contemporary Ethnography 35(4):419-28.

Douglas, Mary. (1966) 2002. Purity and Danger, An Analysis of concept of Pollution and Taboo. London: Routledge.

Downey, Greg. 2005. Learning Capoeira: Lessons in Cunning from an Afro-Brazilian Art. New York: OUP.

Downey, Greg. 2007. Producing Pain: Fighting Techniques and Technologies in No-HoldsBarred Fighting. Social Studies of Science 37(2):201-26.

Du Bois, W.E.B. 1994. The Souls of Black Folk. New York, Avenel, NJ: Gramercy Books.

Ferrari, Matthew P. 2013. Sporting Nature(s): Wildness, the Primitive, and Naturalizing Imagery in MMA and Sports Advertisements. Environmental Communications 7(2)27796.

Gentry, Clyde. 2005. No Holds Barred: Ultimate Fighting and the Martial Arts Revolution. St Paul, MN: Milo Books.

Gentry, Clyde. 2011. No Holds Barred: The Complete History of Mixed Martial Arts in America. Chicago: Triumph Books.

Goodall, Jr. H.L. 2008. Writing Qualitative Inquiry: Self, Stories, and Academic Life. Walnut Creek, California: Left Coast Press, Inc.

Green, Kyle. 2011. It hurts so it is real: sensing the seduction of mixed martial arts. Social \& Cultural Geography 12(4):377-396.

Gubrium, Jaber F. and Holstein, James A. 2002. Handbook of Interview Research: Context and Method. London: Sage Publications.

Hirose, Akihiko and Kei-ho Pih. 2010. Masculinities in Mixed Martial Arts, Men Who Strike and Men Who Submit: Hegemonic and Marginalized Masculinities in Mixed Martial Arts. Men and Masculinities 13(2):190-209.

Holt, Nicholas L. 2003. Representation, legitimation, and autoethnography: An autoethnographic writing story. International Journal of Qualitative Methods, 2(1). Article 2. Retrieved June 1, 2015 from http://www.ualberta.ca/ iiqm/backissues/2_1/pdf/holt.pdf

Jennings, George, Brown, David and Sparkes C Andrew. 2010. 'It can be a religion if you want': Wing Chun Kung Fu as a secular religion. Ethnography 11(4):533-57.

Kristeva, Julia. 1982. Powers of Horror: An Essay on Abjection. New York: Columbia University Press.

Meneley, Anne, and Young J. Donna. 2005. Auto-Ethnographies: The Anthropology of 
Academic Practices. Canada: Broadview Press.

Merleau-Ponty, Maurice. 1964. Primacy of Perception. Evanston: Northwestern University Press.

Merleau-Ponty, Maurice. 2002. Phenomenology of Perception. An Introduction. London: Routledge.

Messner, Mike. 1990. When Bodies are Weapons. International Review for the Sociology of Sports 25(3):203-20.

Milton, Martin. 2004. Being a Fighter: It is a Whole State of Being. Existential Analysis 15(1):116-30.

Minge, Jeanine M. 2007. The Stained Body: A Fusion of Embodied Art on Rape and Love. Journal of Contemporary Ethnography 36(3):252-80.

Muncey, Tessa. 2010. Creating Autoethnographies. India: Sage Publications Ltd.

O'Connell, Barry. 1997. A Son of the Forest and Other Writings. Massachusetts: University of Massachusetts Press.

Olsen, Kevin. 2008. A Narrative Inquiry into an Extreme Sport: The Lived Experience of Skydiving. Master's thesis. The University of Alberta.

Pagis, Michal. 2010. Producing Intersubjectivity in Silence: An Ethnographic Study of Meditation Practice. Ethnography 11(2):309-28.

Poliakoff, B Michael. 1995. Combat Sports in the Ancient World: Competitions, Violence and Culture. New Haven: Yale University Press.

Russell, G. W. 1992. Response of the Macho Male to Viewing a Combatant Sport. Journal of Social Behavior and Personality 7:631-38.

Sánchez, García, Raúl and Malcolm, Dominic. 2010. Decivilizing, civilizing or informalizing? The international development of Mixed Martial Arts. International Review for the Sociology of Sport 45(1):39-58.

Sheridan, Sam. 2007. A Fighter's Heart: One Man's Journey through the World of Fighting. New York: Grove Press, Atlantic.

Sheridan, Sam. 2010. The Fighter's Mind: Inside the Mental Game. New York: Grove Press, Atlantic.

Sparkes, A.C. 2000. Autoethnography and narratives of self: Reflections on criteria in action. Sociology of Sport Journal, 17, 21-43.

Spencer, C. Dale. 2009. Habit(us) Techniques and Body Callusing: An Ethnography of Mixed Martial Arts. Body \& Society 15:119-43.

Spencer, C. Dale. 2012. Ultimate Fighting and Embodiment: Violence, Gender, and Mixed Martial Arts. New York and London: Routledge.

Spencer, C. Dale. 2013. Sensing Violence: An Ethnography of Mixed Martial Arts. Ethnography 0(00):1-23.

Spry, Tarni. 2001. Performing Autoethnography: An Embodied Methodological Praxis. Qualitative Inquiry 7(6):706-32.

Stephens, Neil and Sara Delmont. 2006. Balancing the Berimbau: Embodied Ethnographic Understanding. Qualitative Inquiry 12:316-36.

Turner, Viktor. 1995. The Ritual Process. New Ed. Chicago, USA. Aldine Transaction.

Vaccaro, A. Cristian, Schrock, Douglas P and McCabe, Janice M. 2011. Managing Emotional Manhood: Fighting and Fostering Fear in Mixed Martial Arts. Social Psychology Quarterly 74(4):414-37.

Van Bottenburg, Maarten, and Heilbron, Johan. 2006. De-Sportization of Fighting Contests: The Origins and Dynamics of No Holds Barred Events and the Theory of Sportization. International Review for the Sociology of Sport 41(3-4):259-82.

Van Bottenburg, Maarten and Heilbron, Johan. 2010. Informalization or De-Sportization of Fighting Contests? A Rejoinder to Raul Sánchez García and Dominic Malcolm. 
International Review for the Sociology of Sport 46(1):125-27.

Wacquant, Loïc. 1995. Pugs at Work: Bodily Capital and Bodily Labor among Professional Boxers. Body \& Society 1(1):65-93.

Wacquant, Loïc. 2004. Body and Soul: Notes of an Apprentice Boxer. Oxford: Oxford University.

Woodward, Kath. 2008. Hanging out and hanging about: Insider/outsider research in the sport of boxing. Ethnography 9(4): 536-60.

Wolcott, Harry. 2004. The Ethnographic Autobiography. Auto/Biography 12:93-106. 